\title{
Modeling and electrokinetic evidences on the processes of the Al(III) sorption continuum in $\mathrm{SiO}_{2(s)}$ suspension
}

\author{
Wen Hui Kuan, ${ }^{a, *}$ Shang Lien Lo, ${ }^{\mathrm{b}}$ and Ming Kuang Wang ${ }^{\mathrm{c}}$ \\ ${ }^{a}$ Department of Environmental and Safety Engineering, Ming-Chi Institute of Technology, 84, Gunjuan Rd., Taishan, Taipei Hsien 243, Taiwan \\ ${ }^{\mathrm{b}}$ Graduate Institute of Environmental Engineering, National Taiwan University, Taipei 106, Taiwan \\ ${ }^{\mathrm{c}}$ Department of Agriculture Chemistry, National Taiwan University, Taipei 106, Taiwan
}

Received 30 June 2003; accepted 12 December 2003

\begin{abstract}
Reactions of $\mathrm{Al}(\mathrm{III})$ at the interface between $\mathrm{SiO}_{2(s)}$ and aqueous solution were characteristically and quantitatively studied using electrophoretic methods and applying a surface complexation/precipitation model (SCM/SPM). The surface and bulk properties of $\mathrm{Al}(\mathrm{III}) / \mathrm{SiO}_{2}$ suspensions were determined as functions of $\mathrm{pH}$ and initial $\mathrm{Al}(\mathrm{III})$ concentration. Simulated modeling results indicate that the SCM, accounting for the adsorption mechanism, predicts sorption data for low surface coverage only reasonably well. Al(III) hydrolysis and surface hydroxide precipitation must be invoked as the $\mathrm{Al}(\mathrm{III})$ concentration and/or $\mathrm{pH}$ progressively increase. Accordingly, the three processes in the $\mathrm{Al}(\mathrm{III})$ sorption continuum, from adsorption through hydrolysis to surface precipitation, could be identified by the divergence between the SCM/SPM predictions and the experimental data. $\mathrm{SiO}_{2(s)}$ suspensions with low $\mathrm{Al}(\mathrm{III})$ concentrations $\left(1 \times 10^{-4}\right.$ and $\left.1 \times 10^{-5} \mathrm{M}\right)$ exhibit electrophoretic behavior similar to that of a pure $\mathrm{SiO}_{2(s)}$ system. In $\mathrm{Al}(\mathrm{III}) / \mathrm{SiO} 2$ systems with high Al concentrations of $1 \times 10^{-3}, 5 \times 10^{-3}$ and $1 \times 10^{-2} \mathrm{M}$, three charge reversals (CR) are observed, separately representing, in order of increasing $\mathrm{pH}$, the point of zero charge (PZC) on the $\mathrm{SiO}_{2}$ substrate (CR1), the onset of the surface precipitation of Al hydroxide (CR2), and at a high $\mathrm{pH}$, the $\mathrm{PZC}$ of the $\mathrm{Al}(\mathrm{OH})_{3}$ coating (CR3). Furthermore, in the $1 \times 10^{-3} \mathrm{M} \mathrm{Al}(\mathrm{III}) / \mathrm{SiO}_{2}(s)$ system, CR2 is consistent with the modeling results of SCM/SPM and provides evidence that $\mathrm{Al}(\mathrm{III})$ forms a surface precipitate on $\mathrm{SiO}_{2(s)}$ at $\mathrm{pH}$ above 4 . SiO $2(s)$ dissolution was slightly inhibited when $\mathrm{Al}(\mathrm{III})$ was adsorbed onto the surface of $\mathrm{SiO}_{2(s)}$, as compared to the dissolution that occurs in a pure $\mathrm{SiO}_{2(s)}$ suspension system. Al hydroxide surface precipitation dramatically reduced the dissolution of $\mathrm{SiO}_{2(s)}$ because the Al hydroxide passive film inhibited the corrosion of the $\mathrm{SiO}_{2(s)}$ surface by $\mathrm{OH}^{-}$ions.
\end{abstract}

(c) 2004 Elsevier Inc. All rights reserved.

Keywords: $\mathrm{Al}(\mathrm{III})$; Interface reactions; $\mathrm{SiO}_{2}$; Electrophoretic method; Surface complexation model; Surface precipitation model

\section{Introduction}

Silicon is the second most abundant element in the earth's crust and is present as silicates and silica. Iler [1] divided silica into five different phases, of which anhydrous and hydrous amorphous silica are the most important from a colloidal perspective, since it is this phase that forms colloidal and microporous structures. In acidic lakes and streams throughout the world, aluminum is present in concentrations from several $\mu \mathrm{mol} / 1$ to several hundred $\mu \mathrm{mol} / 1$ [2], that is, at a level toxic to aquatic life [3]. Since the toxicity of Al depends strongly on its speciation (free and complexed $\mathrm{Al}$ )

\footnotetext{
* Corresponding author.

E-mail address: whkuan@ccsun.mit.edu.tw (W.H. Kuan).
}

and mobility (soluble, colloid, or precipitated) [4,5], its interaction with silica may significantly alter the bioavailability of this element and its detrimental effects on aquatic organisms [6,7]. In the water-treatment industry the interactions between silica and aluminum also play a determining role, because $\mathrm{Al}$ salts are common coagulants and silica is a prevalent constituent of solid matter in raw water. Moreover, hydrolyzed aluminum is used to set rosin and dyes in the production of paper and to improve the retention of fillers. The increased use of hydrolyzed aluminum salts has heightened commercial and research interest in aluminum hydrolysis [8,9]. A number of studies on aluminum hydrolysis have emphasized the stoichiometry or kinetics of complex hydrolysis, precipitation, and surface chemical reactions of a pure aluminum system $[9,10]$. Some researchers [11-14] 
have pointed out that soluble aluminum has a high potential to form mixed oxides with other component oxides in natural environments, and the characteristics of such mixed oxides deviate significantly from either average collective properties for the group or a collection of discrete pure solid phases. However, the understanding of when and how the sorption continuum for $\mathrm{Al}(\mathrm{III})$, from soluble free ions to a surface or bulk oxide precipitate, proceeds in $\mathrm{SiO}_{2(s)}$ suspensions is quite limited. Limited knowledge of these processes has restricted the accurate prediction of the distribution of $\mathrm{Al}(\mathrm{III})$ in aquatic systems and the adsorption properties of other trace elements onto the undefined surfaces of these mixed oxides.

When a metal ion is present in an oxide suspension system, a sorption continuum [15] may occur from mononuclear adsorption to hydrolysis, to multinuclear adsorption, or to precipitation on the surface of oxide or in bulk solution; during these processes, system $\mathrm{pH}$ or sorbate/sorbent ratios increase [16-19]. At a low $\mathrm{pH}$ or sorbate/sorbent ratio, cations coordinate with surface functional groups of an oxide; the enhanced interaction between adjacent cations results in a sorption continuum with $\mathrm{pH}$ and/or the sorbate/sorbent ratio increasing. Because adsorption, hydrolysis, and precipitation of $\mathrm{Al}(\mathrm{III})$ occur over a very narrow $\mathrm{pH}$ range, each process of the sorption continuum is difficult to interpret and distinguish [20,21]. Xu et al. [22] also indicated that such processes can proceed simultaneously, and distinguishing them requires analytical methods with molecular-scale resolution.

The following definitions are adopted in the discussion of the mechanism of the interface reactions. According to the relative concentrations and contact methods, interactions between hydrous oxides and metals include (1) sorption, referring to the uptake of a dissolved metal by a solid phase, irrespective of the mechanism [16,23,24]; (2) adsorption, referring to a surface complexation reaction between surface sites and a metal sorbate [25]; and (3) surface precipitation, referring to the formation of a precipitate, induced by the sorbent surface under solution conditions that are undersaturated with respect to any known phase [26-28]. Depending on the type of interaction, metals exhibit various solubilities that can markedly alter their environmental mobility and removal efficiency during wastewater treatment [29-31].

This study aims to identify the reactions that occurred during this sorption continuum of $\mathrm{Al}(\mathrm{III})$ in $\mathrm{SiO}_{2(s)}$ suspension and to clarify how environmental conditions influence these processes. The effects of a wide range of sorbateto-sorbent ratios and $\mathrm{pH}$ were modeled using SCM/SPM to clarify the onset of each process in the sorption continuum. Electrokinetic measurements were performed to determine the nature of the $\mathrm{Al}(\mathrm{III})$ interaction with the $\mathrm{SiO}_{2(s)}$ surface [32]. The measurement of silica dissolution yielded information on the onset of surface precipitation.

\section{Materials and methods}

\subsection{Batch experiments}

Batch experiments concerning $\mathrm{Al}(\mathrm{III})$ sorption onto $\mathrm{SiO}_{2}$ were conducted in 50-ml polypropylene bottles with caps. The used silica $\left(\mathrm{SiO}_{2}\right)$ was Cab-O-Sil M5 (Cabot Corp., Tuscolca, IL), amorphous and fumed silica with a BET surface area of $200 \mathrm{~m}^{2} / \mathrm{g}$ (analyzed by ASAP 2000). Before the batch experiments were performed, the $\mathrm{SiO}_{2}$ suspension was aged at $25^{\circ} \mathrm{C}$ in an $\mathrm{N}_{2}$ atmosphere for $2 \mathrm{~h}$.

Solutions were prepared using reagent-grade chemicals and Millipore-Q water, following standard methods [33]. The initial concentration of $\mathrm{Al}(\mathrm{III})\left(\mathrm{Al}\left(\mathrm{NO}_{3}\right)_{3} \cdot 9 \mathrm{H}_{2} \mathrm{O}\right)$ was $0-1 \times 10^{-2} \mathrm{M}$; the $\mathrm{SiO}_{2}$ concentration was maintained at $1 \mathrm{~g} / \mathrm{l}$, and the background electrolyte concentration was adjusted to $0.1 \mathrm{M}$ by $\mathrm{KNO}_{3}$ electrolyte solution. All experiments were performed at $25^{\circ} \mathrm{C}$, after adjustment to the desired $\mathrm{pH}$ using $\mathrm{KOH}$ and $\mathrm{HNO}_{3}$ solutions, with shaking at $200 \mathrm{rpm}$. Since preliminary kinetic experiments suggested that pseudo-equilibrium was reached within $24 \mathrm{~h}, 24 \mathrm{~h}$ was selected as the reaction time for the equilibrium experiments [34].

To elucidate these processes in the sorption continuum, samples were prepared in which $\mathrm{SiO}_{2(s)}$ powder was equilibrated with $\mathrm{Al}(\mathrm{III})$ aqueous solutions with concentrations from undersaturated to oversaturated, with respect to the bulk phase precipitation in the absence of a solid sorbent. Two parameters, $\mathrm{pH}$ and total $\mathrm{Al}(\mathrm{III})$ concentration, were studied in batch experiments to determine sorption $\mathrm{pH}$ edges and isotherms, respectively. After the reaction, a subsample of the suspension was taken for electrophoresis measurements; the rest of the suspension was centrifuged (Kubota 6800 ) at $10,000 \mathrm{rpm}$ for $15 \mathrm{~min}$ and the supernatant was passed through a $0.2-\mu \mathrm{m}$ membrane filter to analyze the soluble $\mathrm{Al}$ and the $\mathrm{Si}$ dissolved out of bulk $\mathrm{SiO}_{2(s)}$ solid by an ICP-AES (Perkin-Elmer, Optima 2000DV).

\subsection{Electrophoresis measurements}

Electrophoretic mobility (EM) was measured at various $\mathrm{pH}$ and $\mathrm{Al}(\mathrm{III})$ concentrations to detect changes in net total particle surface charge density associated with the sorption of $\mathrm{Al}(\mathrm{III})$. The electrophoretic mobility of the particles in $\mathrm{SiO}_{2}$ suspensions with various amounts of $\mathrm{Al}(\mathrm{III})$ at $\mathrm{pH}$ values between 1.5 and 12.0 was measured using a laser Doppler electrophoretic light-scattering apparatus (Malvern Instrument, Zetasizer 2000). Triplicate measurements were made in crossed-beam mode with a 30-s count time, an applied voltage of $150 \mathrm{~V}$, and a modulator frequency of $1000 \mathrm{~Hz}$.

\subsection{Modeling approaches}

Three categories of surface reaction were consideredsurface complexation, surface precipitation, and bulk precip- 
Table 1

Category of surface reactions

\begin{tabular}{|c|c|c|c|}
\hline Category & Applied model & Forming species & Abbreviation \\
\hline \multirow[t]{2}{*}{ Surface complexation } & \multirow[t]{2}{*}{$\mathrm{SCM}$} & Adsorption of hexaqua- $\mathrm{Al}^{3+}$ ion $\left(\mathrm{Al}\left(\mathrm{H}_{2} \mathrm{O}\right)_{6}^{3+}\right)$ onto $\mathrm{SiO}_{2(s)}$ & AA \\
\hline & & Adsorption of 1 st hydrolyzed hexaqua- $\mathrm{Al}^{3+}$ ion $\left(\mathrm{Al}(\mathrm{OH})\left(\mathrm{H}_{2} \mathrm{O}\right)_{5}^{2+}\right)$ onto $\mathrm{SiO}_{2(s)}$ & $\mathrm{AH}$ \\
\hline Surface precipitation & \multirow[t]{2}{*}{ SPM } & $\begin{array}{l}\text { Coprecipitation of } \mathrm{Al}(\mathrm{III}) \text { hydroxide phase as a solid solution with the original } \mathrm{SiO}_{2(s)} \\
\text { surface phase }\end{array}$ & PS \\
\hline Bulk precipitation & & Precipitation of $\mathrm{Al}(\mathrm{OH})_{3(s)}$ in bulk solution & PB \\
\hline
\end{tabular}

Table 2

Fixed parameters for modeling with SCM and SPM

\begin{tabular}{lr}
\hline Site concentration of $\mathrm{SiO}_{2(s)}(\mathrm{mmol} / \mathrm{g})$ & $1.67^{\mathrm{a}}$ \\
Surface area of $\mathrm{SiO}_{2(s)}\left(\mathrm{m}^{2} / \mathrm{g}\right)$ & $200^{\mathrm{b}}$ \\
$\log K_{a_{1}}^{\mathrm{int}}$ & $-1.5^{\mathrm{a}}$ \\
$\log K_{a_{2}}^{\mathrm{int}}$ & $-5.5^{\mathrm{a}}$ \\
$\log K_{\mathrm{sp}} \mathrm{Al}$ & $10.38^{\mathrm{c}}$ \\
$\log K_{\mathrm{sp} \_\mathrm{Si}}$ & $-2.74^{\mathrm{c}}$ \\
\hline a Meng and Letterman $[13,14]$. & \\
b Measured in this study. & \\
c Database of MINTEQA2 program. &
\end{tabular}

itation-to describe the sorption continuum. In each reaction category, $\mathrm{Al}(\mathrm{III})$ forms several surface species, depending on the system conditions (Table 1).

\subsubsection{Surface complexation model (SCM)}

The geochemical speciation code MINTEQA2, Version 3.11 [35], was used to simulate the equilibrium partition of $\mathrm{Al}(\mathrm{III})$ in the $\mathrm{SiO}_{2(s)}$ /aqueous solution. The $\mathrm{SiO}_{2(s)}$ surface parameters were adopted from the work of Meng and Letterman $[13,14]$ and are presented in Table 2. Both the diffuse layer model (DLM) and the database included in the MINTEQA2 were used for surface complexation modeling. The DLM was a type of simple two-layer model, including one planar surface layer and one diffuse layer of counterions [36]. The exponential coulombic term derived from Gouy and Chapman's electrical double layer theory (EDL) was introduced to correct the surface-reaction mass-law constants for surface charge effects [32]. Table 3 summarizes the surface reactions considered in the SCM (Eqs. (1)-(4)).

\subsubsection{Surface precipitation model (SPM)}

Farley et al. [37] extended the DLM to include surface precipitation by taking into account the formation of a new surface phase, which is described as an ideal solid solution $[38,39]$ of $\mathrm{Me}(\mathrm{OH})_{2(s)}$ and $\mathrm{Fe}(\mathrm{OH})_{3(s)}$. This approach yields a continuum between the adsorption of a solute on a surface and the precipitation of this solute as a new bulk solid phase. In this study, the model was modified and applied to the $\mathrm{Al}(\mathrm{III}) / \mathrm{SiO}_{2(s)}$ system.

The success of the surface precipitation model follows from the fact that it provides a mathematical approach to increasing the activity of the coprecipitating solid metal hydroxide phase continuously from near zero to unit activity as the amount of surface precipitate that forms increases. This continuous increase is accomplished by assuming that an ideal solid solution is generated by

$$
\left\{\mathrm{Al}(\mathrm{OH})_{3(s)}\right\}=\frac{\left[\mathrm{Al}(\mathrm{OH})_{3(s)}\right]}{T_{S}}
$$

and

$\left\{\mathrm{SiO}_{2(s)}\right\}=\frac{\left[\mathrm{SiO}_{2(s)}\right]}{T_{s}}$,

where \{ $\}$ and [ ], respectively, represent the activity and molal concentration of the corresponding species, and $T_{S}$ represents the total mass of solid material in solid solution and is given by

$T_{s}=\left[\mathrm{Al}(\mathrm{OH})_{3(s)}\right]+\left[\mathrm{SiO}_{2(s)}\right]$.

Additionally, an ideal solid solution is assumed, so

$\left\{\mathrm{Al}(\mathrm{OH})_{3(s)}\right\}+\left\{\mathrm{SiO}_{2(s)}\right\}=1$.

This representation allows the solubility of the aluminum hydroxide phase to decline at lower surface coverages. For

Table 3

Surface reactions considered in SCM

\begin{tabular}{|c|c|c|}
\hline Reaction & \multicolumn{2}{|l|}{ Equilibrium constant expression } \\
\hline \multicolumn{3}{|c|}{ Surface ionization } \\
\hline $\mathrm{SOH}+\mathrm{H}^{+} \rightleftarrows \mathrm{SOH}_{2}^{+}$ & $K_{a_{1}}^{\mathrm{int}}=\exp (F \varphi / R T)\left[\mathrm{SOH}_{2}^{+}\right] /[\mathrm{SOH}]\left[\mathrm{H}^{+}\right]$ & (1) \\
\hline $\mathrm{SOH} \rightleftarrows \mathrm{SO}^{-}+\mathrm{H}^{+}$ & $K_{a_{2}}^{\mathrm{int}}=\exp (-F \varphi / R T)\left[\mathrm{SO}^{-}\right]\left[\mathrm{H}^{+}\right] /[\mathrm{SOH}]$ & (2) \\
\hline \multicolumn{3}{|c|}{ Surface complexation } \\
\hline $\mathrm{SOH}+\mathrm{Al}^{3+} \rightleftarrows \mathrm{SOAl}^{2+}+\mathrm{H}^{+}$ & $K_{\mathrm{AA}}^{\mathrm{int}}=\exp (2 F \varphi / R T)\left[\mathrm{SOAl}^{2+}\right]\left[\mathrm{H}^{+}\right] /[\mathrm{SOH}]\left[\mathrm{Al}^{3+}\right]$ & (3) \\
\hline $\mathrm{SOH}+\mathrm{Al}^{3+}+\mathrm{H}_{2} \mathrm{O} \rightleftarrows \mathrm{SOAlOH}^{+}+2 \mathrm{H}^{+}$ & $K_{\mathrm{AH}}^{\mathrm{int}}=\exp (F \varphi / R T)\left[\mathrm{SOAlOH}^{+}\right]\left[\mathrm{H}^{+}\right]^{2} /[\mathrm{SOH}]\left[\mathrm{Al}^{3+}\right]$ & (4) \\
\hline
\end{tabular}

$F$ : Faraday constant; $\phi$ : the potential at the $\mathrm{SiO}_{2(s)}$ surface; $R$ : gas constant; $T$ : absolute temperature. 
example, the aluminum hydroxide phase forms when the $\mathrm{Al}(\mathrm{III})$ ion activity product (IAP) is exceeded, according to

$\mathrm{IAP}=\left\{\mathrm{Al}^{3+}\right\}\left\{\mathrm{OH}^{-}\right\}^{3}=\left\{\mathrm{Al}(\mathrm{OH})_{3(s)}\right\} K_{\text {sp_Al }}$,

where $K_{\mathrm{Sp} \_\mathrm{Al}}$ is the thermodynamic solubility product constant of $\mathrm{Al}(\mathrm{OH})_{3(s)}$. According to Eq. (5), as $\left\{\mathrm{Al}(\mathrm{OH})_{3(s)}\right\}$ decreases, the value of the IAP required for the onset of precipitation decreases. Hence, surface precipitation can occur at $\mathrm{Al}(\mathrm{III})$ ion concentrations and $\mathrm{pH}$ values below those required for precipitation of the pure solid phase from aqueous solution. A solid-phase activity continuously increasing from almost zero to unity has been found to be necessary to enable the solid solution model to describe $\mathrm{Al}(\mathrm{III})$ ion sorption as a function of the changing surface coverage.

In this model, $\mathrm{Al}(\mathrm{III})$ at the $\mathrm{SiO}_{2(s)}$ /aqueous solution interface is treated as a surface species, while $\mathrm{Al}(\mathrm{III})$ is not in direct contact with the solution phase; that is, it is buried under the $\mathrm{SiO}_{2(s)}$ /aqueous solution interface and is treated as a solid species (denoted by subscript $(s)$ ) that forms a solid solution. Surface precipitation reactions involved in the uptake of $\mathrm{Al}(\mathrm{III})$ by $\mathrm{SiO}_{2(s)}$ can then be written as follows:

Adsorption of $\mathrm{Al}(\mathrm{III})$ onto $\mathrm{SiO}_{2(s)}$

$$
\begin{aligned}
& \equiv \mathrm{Si}-\mathrm{OH}^{0}+\mathrm{Al}^{3+}+3 \mathrm{H}_{2} \mathrm{O} \\
& \rightleftarrows \mathrm{SiO}_{2(s)}+\equiv \mathrm{Al}-\mathrm{OH}_{2}^{+}+2 \mathrm{H}^{+}, \quad K_{\mathrm{PS}}^{\mathrm{int}} .
\end{aligned}
$$

Precipitation of $\mathrm{Al}(\mathrm{III})$

$$
\begin{aligned}
\equiv & \mathrm{Al}-\mathrm{OH}_{2}^{+}+\mathrm{Al}^{3+}+3 \mathrm{H}_{2} \mathrm{O} \\
& \rightleftarrows \mathrm{Al}(\mathrm{OH})_{3(s)}+\equiv \mathrm{Al}-\mathrm{OH}_{2}^{+}+3 \mathrm{H}^{+}, \quad 1 / K_{\mathrm{sp} \_\mathrm{Al}} . \\
& \text { Adsorption of } \mathrm{Si}(\mathrm{OH})_{4} \text { on } \mathrm{Al}(\mathrm{OH})_{3(s)} \\
\equiv & \mathrm{Al}-\mathrm{OH}_{2}^{+}+\mathrm{Si}(\mathrm{OH})_{4(\mathrm{aq})} \\
& \rightleftarrows \mathrm{Al}(\mathrm{OH})_{3(s)}+\equiv \mathrm{Si}-\mathrm{OH}^{0}+\mathrm{H}^{+}+2 \mathrm{H}_{2} \mathrm{O}, \\
& 1 / K_{\mathrm{PS}}^{\mathrm{int}} K_{\mathrm{sp} \_\mathrm{Al}} K_{\mathrm{sp} \_\mathrm{Si}} . \\
& \text { Precipitation of } \mathrm{Si}(\mathrm{OH})_{4} \\
\equiv & \mathrm{Si}-\mathrm{OH}^{0}+\mathrm{Si}(\mathrm{OH})_{4(\mathrm{aq})} \\
& \rightleftarrows \mathrm{SiO}_{2(s)}+\equiv \mathrm{Si}-\mathrm{OH}^{0}+2 \mathrm{H}_{2} \mathrm{O}, \quad 1 / K_{\mathrm{sp} \_\mathrm{Si}} .
\end{aligned}
$$

The surface symbols $\equiv$ and $\equiv$ are used to denote the bonds of the cations with the surface of the solid, and have different meanings for $\mathrm{Si}(\mathrm{IV})$ and $\mathrm{Al}(\mathrm{III})$ : $\equiv \mathrm{Si}-\mathrm{OH}^{0}$ represents $\left[\mathrm{SiO}_{2}\right]_{n}$ because $\mathrm{SiO}_{2}$ is a tetrahedron, with four $\mathrm{O}$ atoms bonded to each $\mathrm{Si}$ atom, and $\equiv \mathrm{Al}-\mathrm{OH}^{0}$ represents $\left[\mathrm{Al}(\mathrm{OH})_{3}\right]_{n}$ because $\mathrm{Al}(\mathrm{OH})_{3}$ is an octahedron, with three $\mathrm{O}$ atoms bonded to each $\mathrm{Al}$ atom. Thus reactions (10) and (12) are balanced with respect to $\mathrm{H}$ and $\mathrm{O}[37,40]$. Although the surface species indicated in reactions (11) and (13) divide out of the corresponding mass law expressions, they are included to emphasize the link between adsorption and surface precipitation. The term $K_{\mathrm{PS}}^{\mathrm{int}}$ represents the intrinsic equilibrium constant for $\mathrm{Al}(\mathrm{III})$ precipitation, and $K_{\mathrm{sp} \_} \mathrm{Si}$ is the thermodynamic solubility product constant of $\mathrm{SiO}_{2(s)}$. Importantly, only three of the four equations (10)-(13) are mathematically independent expressions. Table 2 presents the parameters used to model surface precipitation.

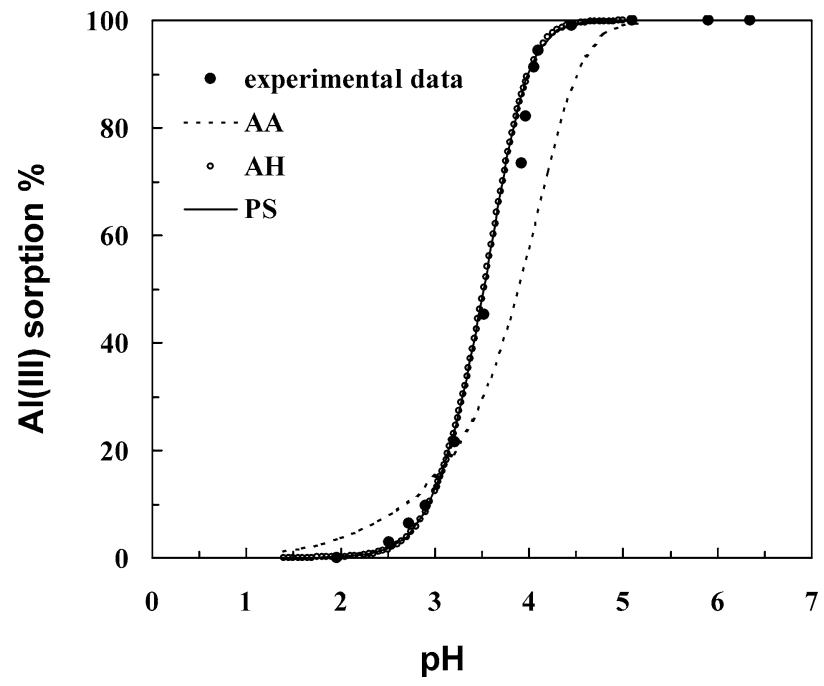

Fig. 1. Percentage of $\mathrm{Al}$ sorption vs $\mathrm{pH}$ and DLM simulation results of $1 \times 10^{-4} \mathrm{M} \mathrm{Al}(\mathrm{III}) / \mathrm{SiO}_{2(s)}$ system. Three predictions according to adsorption of $\mathrm{Al}^{3+}$ ion (AA), adsorption of $\mathrm{AlOH}^{2+}$ ion (AH), and surface precipitation (PS) reactions are given for comparison. Fitting parameters are as follows: $\log K_{\mathrm{AA}}^{\mathrm{int}}=0.5, \log K_{\mathrm{AH}}^{\mathrm{int}}=-3$, and $\log K_{\mathrm{PS}}^{\mathrm{int}}=-4.8$.

\section{Results and discussion}

\subsection{Al(III) sorption and simulation of SCM/SPM}

The effect of the change in the concentration of the background electrolyte $\left(\mathrm{KNO}_{3}\right)$ on the $\mathrm{Al}(\mathrm{III})$ sorption onto $\mathrm{SiO}_{2(s)}$ was examined before the $\mathrm{pH}$-edge and isotherm experiments to clarify the strength of the bonding between $\mathrm{Al}(\mathrm{III})$ and the $\mathrm{SiO}_{2(s)}$ surface. The experimental results revealed that ionic strength did not affect the sorption of $\mathrm{Al}(\mathrm{III})$ onto $\mathrm{SiO}_{2(s)}$ (figure not shown). This finding suggests that $\mathrm{Al}$ (III) tends to form an inner-sphere complex, which bonds strongly to the $o$-plane [41]. From previous studies, the structure of strongly sorbed surface species is generally described as monodentate or bidentate inner-sphere complexes at low and moderate surface coverage, and as multinuclear species and surface precipitation at high surface coverage [17-19,42].

Fig. 1 shows the model predictions of $1 \times 10^{-4} \mathrm{M}$ $\mathrm{Al}(\mathrm{III})$ reactions in $\mathrm{SiO}_{2(s)}$ suspensions at various $\mathrm{pH}$ for the AA, AH, and PS configurations (Table 1) considered in SCM/SPM. The experimental results display that $\mathrm{Al}(\mathrm{III})$ sorption onto $\mathrm{SiO}_{2(s)}$ increases with the $\mathrm{pH}$ value. The $\mathrm{AH}$ and PS configurations excellently fit the experimental data and both appear as one line, while the AA type does not satisfactorily describe $\mathrm{Al}(\mathrm{III})$ behavior in this region of the envelope curve. The results of the PB simulation were ignored because homogeneous $\mathrm{Al}$ hydroxides cannot precipitate in such a low initial concentration of $\mathrm{Al}(\mathrm{III})$, according to the solubility product constant of $\mathrm{Al}(\mathrm{OH})_{3(s)}$. As the modeling results suggest, the adsorption mechanism dominates the uptake of $1 \times 10^{-4} \mathrm{M} \mathrm{Al}(\mathrm{III})$. Crawford et al. [43] stated that the dielectric constant of the solid substrate plays a major role in determining the pattern of the complex species dur- 


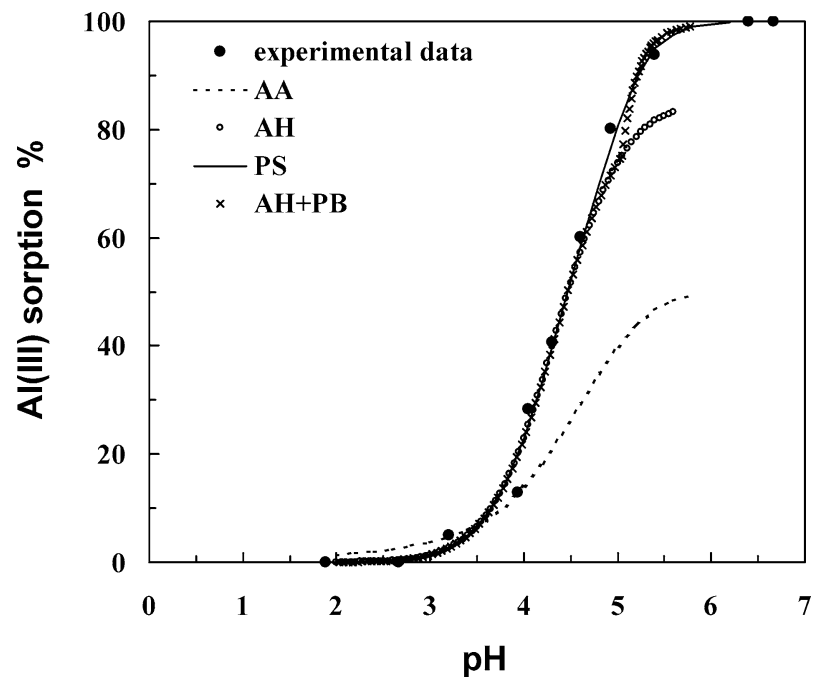

Fig. 2. Percentage of $\mathrm{Al}$ sorption vs $\mathrm{pH}$ and DLM simulation results of $1 \times 10^{-3} \mathrm{M} \mathrm{Al}(\mathrm{III}) / \mathrm{SiO}_{2(s)}$ system. Four predictions according to adsorption of $\mathrm{Al}^{3+}$ ion (AA), adsorption of $\mathrm{AlOH}^{2+}$ ion (AH), surface precipitation (PS), and adsorption of $\mathrm{AlOH}^{2+}$ ion incorporated with bulk precipitation $(\mathrm{AH}+\mathrm{PB})$ reactions are given for comparison. Fitting parameters are as follows: $\log K_{\mathrm{AA}}^{\mathrm{int}}=0.5, \log K_{\mathrm{AH}}^{\mathrm{int}}=-4, \log K_{\mathrm{PS}}^{\mathrm{int}}=-5.8$.

ing metal ion adsorption. The dominant sorbing species is the free metal ions when a solid substrate with a dielectric constant $(\epsilon)$ approaching that of water $(\epsilon=78.3)$ is used. However, the hydrolysis product of metal ions is the dominant adsorbing species when a solid substrate with a low dielectric constant is used. Accordingly, $\mathrm{AlOH}^{2+}$ is the dominant adsorbing species in this system since the dielectric constant of $\mathrm{SiO}_{2}(\epsilon=6)$ is much less than that of water.

Fig. 2 presents the model-predicted and experimental data for $1 \times 10^{-3} \mathrm{M} \mathrm{Al}(\mathrm{III})$ reactions between $\mathrm{SiO}_{2(s)}$ and solution as a function of $\mathrm{pH}$. As illustrated, attempts to describe the $\mathrm{pH}$-edge data using the adsorption of $\mathrm{Al}^{3+}$ ions (AA type in SCM) were unsuccessful above $\mathrm{pH}$ 3. This results could be attributed to the fact that the hydrolysis of free $\mathrm{Al}^{3+}$ ions occurs above $\mathrm{pH} 3$, and the hydrolyzed species $\left(\mathrm{AlOH}^{2+}\right.$, $\mathrm{Al}_{2}(\mathrm{OH})_{2}^{4+}$, and $\left.\mathrm{Al}_{3}(\mathrm{OH})_{4}^{5+}\right)$ begin to dominate [44]. Simulation that involves the $\mathrm{AH}$ type successfully describes the interfacial behavior of $\mathrm{Al}$ (III) below $\mathrm{pH} 4$, but significantly underestimates the experimental data above $\mathrm{pH} 4$, where high surface loading occurs. Other combinations of reactions were considered to improve the fitness of predictions and explore the events that occurred at high $\mathrm{pH}$. The predictions based on $\mathrm{AH}$ configuration incorporated with the reaction of homogeneous precipitation of $\mathrm{Al}(\mathrm{OH})_{3 \text { (amporphos) (in the }}$ database of the MINTEQA2 Program, v. 3.1) in bulk solution (PB) were denoted as crosses in Fig. 2. The AH $+\mathrm{PB}$ modeling curve has a discontinuous point at $\mathrm{pH} 5$ and then rises gradually to meet the experimental data as $\mathrm{pH}$ increases. Consequently, the increase in the removal of $\mathrm{Al}$ (III) above $\mathrm{pH} 5$ can be attributed primarily to Al hydroxide deposition in bulk solution. Two possible reasons account for the underestimation of SCM from $\mathrm{pH} 4$ to 5: (a) saturation of $\mathrm{SiO}_{2(s)}$ surface sites with increasing $\mathrm{Al}(\mathrm{III})$ sorption, and

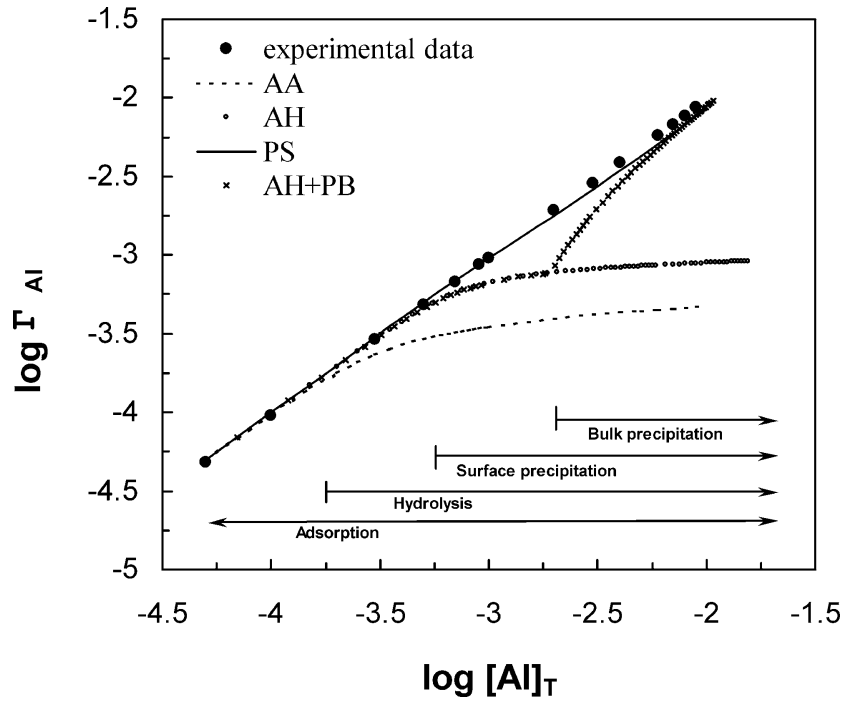

Fig. 3. Modeling $\mathrm{Al}(\mathrm{III})$ sorption isotherm using diffusion-layer model. Four predictions according to adsorption of $\mathrm{Al}^{3+}$ ion (AA), adsorption of $\mathrm{AlOH}^{2+}$ ion (AH), surface precipitation (PS), and adsorption of $\mathrm{AlOH}^{2+}$ ion incorporated with bulk precipitation $(\mathrm{AH}+\mathrm{PB})$ reactions are given for comparison. Fitting parameters are as follows: $\log K_{\mathrm{AA}}^{\mathrm{int}}=0.5$, $\log K_{\mathrm{AH}}^{\mathrm{int}}=-4, \log K_{\mathrm{PS}}^{\mathrm{int}}=-5.8$.

(b) failure to account for $\mathrm{Al}(\mathrm{III})$ polymerization and surface precipitation [31]. When the number of surface sites of $\mathrm{SiO}_{2}$ is taken to be $8.35 \mu \mathrm{mol} / \mathrm{m}^{2}$ (calculated by data in Table 2), the $1 \times 10^{-3} \mathrm{M} \mathrm{Al}(\mathrm{III})$ sorbed by $\mathrm{SiO}_{2}$ suspension in the range $\mathrm{pH} 4-5$ occupies just $14 \%$ to $48 \%$ of the sites. This phenomenon implies that the postulate (a), insufficiency of surface sites for $\mathrm{Al}(\mathrm{III})$ removal, does not apply to this system because of the surface geometry [24]. With reference to postulate (b), Fig. 2 indicates that the surface precipitation model with the solid solution assumption reasonably fits the data over the whole range of experimental $\mathrm{pH}$. Therefore, surface precipitation occurs at $\mathrm{pH} 4$, which is about one $\mathrm{pH}$ unit lower than for homogeneous $\mathrm{Al}$ hydroxide precipitation. Over the $\mathrm{pH}$ range from 4 to 5, surface precipitation is the dominant reaction in this system. A number of researchers have demonstrated that the SCMs are satisfactory only for low surface loading, while SPM can provide reasonable fits to the data over a wide range of coverage conditions, from low to high [18,19,30,31,37,40,45]. Increasing the initial concentration of $\mathrm{Al}(\mathrm{III})$ by one order of magnitude $\left(1 \times 10^{-4}-1 \times 10^{-3} \mathrm{M}\right)$ results in a great variety of governing surface reactions; therefore, both the $\mathrm{pH}$ and the sorbate/sorbent ratio importantly affect sorbate reactions at the solid/solution interface.

The effect of sorbate-to-sorbent ratio on surface reaction is depicted using sorption isotherms at $\mathrm{pH} 4.80 \pm 0.03$ (Fig. 3), where total $\mathrm{Al}(\mathrm{III})$ concentration $\left(\log [\mathrm{Al}]_{T}\right)$ is plotted against sorption density $\left(\log \Gamma_{\mathrm{Al}}\right.$, where $\Gamma_{\mathrm{Al}}$ is mole $\mathrm{Al}(\mathrm{III})$ uptake per gram of $\mathrm{SiO}_{2}$ solid). This isotherm experimental data plotted in double logarithmic format follow a linear trend with unit slope over the whole range of total $\mathrm{Al}(\mathrm{III})$ concentrations. Karthikeyan et al. [30,31] tested 
the sorption of copper onto hydrous oxides of iron and aluminum and found out that the copper isotherms for both oxides have an initial region with unit slope at low total $\mathrm{Cu}$ and a Freundlich region with a slope of less than 1:1 at moderate $\mathrm{Cu}$ concentrations. A saturation region also exists, in which $\mathrm{Cu}$ removal increases sharply with total $\mathrm{Cu}$, since all the sorbent reactive sites are fully occupied and $\mathrm{Cu}$ is removed by precipitation reactions. The linear and Freundlich regions in the isotherm can account for the two types of reactive sites high and low binding strength, for $\mathrm{Cu}$ uptake by iron or aluminum oxide surfaces. However, the isotherm data for $\mathrm{Al}(\mathrm{III})$ in this study all follow a linear trend with unit slope over the entire range of total $\mathrm{Al}(\mathrm{III})$ concentrations, even in the zone where homogeneous $\mathrm{Al}$ hydroxide precipitate may be formed. This result implies that there is only one reactive site with the same binding strength for $\mathrm{Al}(\mathrm{III})$ uptake by $\mathrm{SiO}_{2(s)}$ surface, and at high $\mathrm{Al}(\mathrm{III})$ concentrations, some reactions lead to a transition between adsorption and bulk precipitation. Attempts to describe these isotherm data using SCM, illustrating adsorption of various Al species (AA and AH), SPM, assuming a solid solution formed on the surface (PS), and homogeneous precipitate of $\mathrm{Al}$ hydroxide in bulk solution (PB) are shown in Fig. 3. As illustrated in Fig. 3, all models yield suitable fits at low surface coverage, but only SPM reasonably fits the data at high surface coverage. Therefore, the onset and domains of adsorption, hydrolysis, surface precipitation, and bulk precipitation are delineated from the divergence between the model predictions and the isotherm data. Assuming adsorption of free $\mathrm{Al}^{3+}$ ions (AA) and $\mathrm{AlOH}^{2+}(\mathrm{AH})$ resulted in the model's fitting satisfactorily up to a surface coverage of $10^{-3.25} \mathrm{~mol} \mathrm{Al}(\mathrm{III}) / \mathrm{g} \mathrm{SiO}_{2(s)}$. This value of coverage also indicates the onset of surface precipitation. To clarify the surface and bulk precipitation, a homogeneous precipitation reaction of $\mathrm{Al}(\mathrm{OH})_{3(s)}$ incorporated with the adsorption of $\mathrm{AlOH}^{2+}(\mathrm{AH}+\mathrm{PB})$ is also considered. In Fig. 3 , the predictions using $\mathrm{AH}+\mathrm{PB}$ include a discontinuous point at surface coverage of $10^{-2.75} \mathrm{~mol}$ $\mathrm{Al}(\mathrm{III}) / \mathrm{g} \mathrm{SiO}_{2(s)}$ and underestimate the range of surface coverage between $10^{-3.25}$ and $10^{-2.25} \mathrm{~mol} \mathrm{Al}(\mathrm{III}) / \mathrm{g} \mathrm{SiO}_{2(s)}$, which can be regarded as the onset of the bulk precipitation of $\mathrm{Al}(\mathrm{OH})_{3(s)}$ and the surface precipitation domain, respectively.

\subsection{Evidences from electrophoretic mobility (EM) measurements}

In the authors' earlier study, the $\mathrm{EM}$ of pure $\mathrm{SiO}_{2}$ suspensions over a range of $\mathrm{pH}$ values and in three different salt solutions $(0,0.1,0.5 \mathrm{M})$ lie on a curve and the isoelectric point (IEP) is 2.00 for an $\mathrm{SiO}_{2}$ particle [34]. Therefore, $0.1 \mathrm{M} \mathrm{KNO}_{3}$ was adopted as the background electrolyte in all experiments. Fig. 4 shows the EM data of $\mathrm{SiO}_{2}$ suspension with various $\mathrm{Al}$ (III) concentrations as a function of $\mathrm{pH}$. The electrophoretic behavior of $\mathrm{SiO}_{2}$ with $1 \times 10^{-5}$ and $1 \times 10^{-4} \mathrm{M}$ of $\mathrm{Al}(\mathrm{III})$ is similar to that of pure $\mathrm{SiO}_{2}$ suspension. Meng and Letterman [13] also measured the

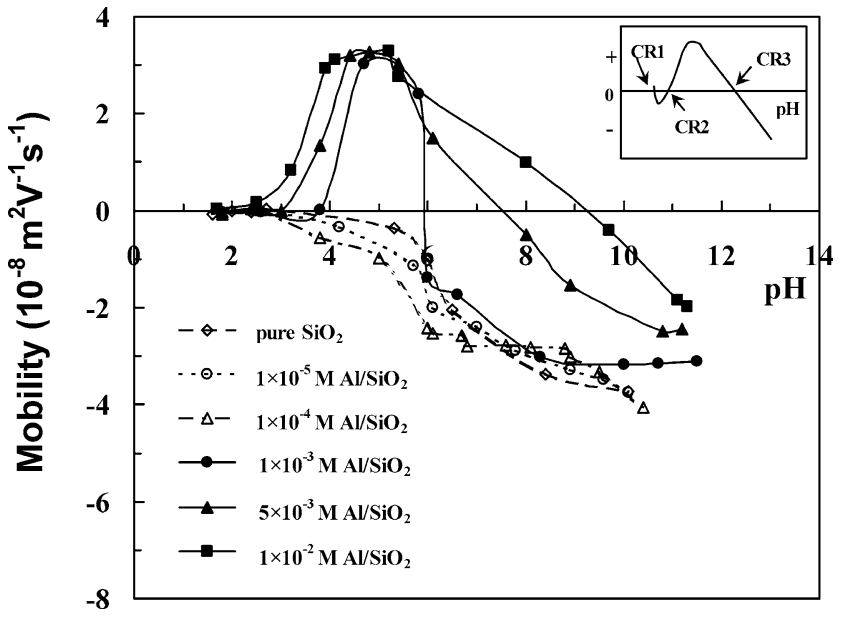

Fig. 4. The $\mathrm{EM}$ of $\mathrm{Al}(\mathrm{III}) / \mathrm{SiO}_{2}$ suspensions as a function of $\mathrm{pH}$ in $0.1 \mathrm{M}$ $\mathrm{KNO}_{3}$ electrolyte in the presence or absence of various concentrations of $\mathrm{Al}(\mathrm{III})$.

zeta potential of $\mathrm{Al}(\mathrm{III}) / \mathrm{SiO}_{2(s)}$ suspensions, but the tested $\mathrm{Al}(\mathrm{III})$ concentration was too high to observe electrokinetic behavior similar to that in pure $\mathrm{SiO}_{2}$ suspension. James and Healy [20] examined the electrophoretic behavior of $\mathrm{La}$ (III) in a $\mathrm{SiO}_{2(s)}$ suspension system and obtained similar results, with no significant shift in electrophoretic mobility, for low specific adsorption amounts of $\mathrm{La}(\mathrm{III})$.

Three charge reversal (CR) points (strictly, the $\mathrm{pH}$ values at which the electrokinetic potential reverses), CR1 (charge reversal from + to - ), CR2 (charge reversal from - to + ), and CR3 (charge reversal from + to - ), correspond to increasing $\mathrm{pH}$ for the curves of $\mathrm{SiO}_{2}$ with $1 \times 10^{-3}, 5 \times 10^{-3}$, and $1 \times 10^{-2} \mathrm{M}$ of $\mathrm{Al}(\mathrm{III})$. The top right corner of Fig. 4 schematically depicts the general features of these electrokinetic curves, including charge reversals. Several recent spectroscopic studies $[17,18,46,47]$ demonstrated that the value of $10 \%$ surface coverage is a criterion for the structure of surface complexes. The inner-sphere monomeric reactions can describe the sorption phenomenon in the low- and moderate coverage range (up to $10 \%$ ). As coverage increases beyond $10 \%$ (high-coverage region), spectroscopic evidence is consistent with the formation of multinuclear species and surface precipitation. This study utilizes two coverage classification schemes, based on the percentage of occupied surface active sites and the area percentage covered by hydrated $\mathrm{Al}^{3+}$ ions with an assumed hydrated radius (H.R.) of $3 \AA$, to elucidate the surface electrophoretic behavior as a function of surface coverage. Table 4 presents the surface coverage values calculated at the $50 \% \mathrm{Al}(\mathrm{III})$ uptake point on the $\mathrm{pH}$ edge for the specified conditions. Each $\mathrm{pH}$ edge yielded a range of surface coverages, extending from $0 \%$ to twice the value shown in Table 4 . For the $1 \times 10^{-5}$ and $1 \times 10^{-4} \mathrm{M} \mathrm{Al}(\mathrm{III}) / \mathrm{SiO}_{2(s)}$ systems with electrophoretic behavior similar to that of pure $\mathrm{SiO}_{2(s)}$ suspension, both the coverage of the area and the site density are lower than $10 \%$, within the range in which inner-sphere monomeric reactions occur [18]. Both the area and the site concentra- 
Table 4

Surface coverage for $\mathrm{Al}(\mathrm{III})$ sorption $\mathrm{pH}$ edges in $\mathrm{SiO}_{2(s)}$ suspension system

\begin{tabular}{ccc}
\hline $\begin{array}{c}\text { Total Al(III) conc. } \\
(\mathrm{mol} / \mathrm{l})\end{array}$ & $\begin{array}{c}\text { Coverage of } 50 \% \\
\text { uptake }\left(\mu \mathrm{mol} / \mathrm{m}^{2}\right)\end{array}$ & $\begin{array}{c}\text { Coverage for area, } \\
\text { H.R. of } \mathrm{Al}^{3+}=3 \AA(\%)\end{array}$ \\
\hline $1 \times 10^{-5}$ & 0.025 & 0.42 \\
$1 \times 10^{-4}$ & 0.25 & 4.24 \\
$1 \times 10^{-3}$ & 2.5 & 42.41 \\
$5 \times 10^{-3}$ & 12.5 & 212.06 \\
$1 \times 10^{-2}$ & 25 & 424.12 \\
\hline
\end{tabular}

tion coverage of the $1 \times 10^{-3}, 5 \times 10^{-3}$, and $1 \times 10^{-2} \mathrm{M}$ $\mathrm{Al}(\mathrm{III}) / \mathrm{SiO}_{2(\mathrm{~S})}$ system are beyond $10 \%$, the electrophoretic behavior in these systems clearly differ from that of the $1 \times 10^{-5}$ and $1 \times 10^{-4} \mathrm{M} \mathrm{Al}(\mathrm{III}) / \mathrm{SiO}_{2(s)}$ systems. Thus, the electrophoretic behavior reflects the mechanism of $\mathrm{Al}(\mathrm{III})$ sorption onto the surface of $\mathrm{SiO}_{2(s)}$.

These experiments do not reveal any significant shift in $\mathrm{CR} 1$ with the concentration of $\mathrm{Al}(\mathrm{III})$. The significance of $\mathrm{CR} 1$ is clear in that $\mathrm{H}^{+}$and $\mathrm{OH}^{-}$ions are potential determinants for the original oxide; thus, CR1 is the point of zero charge (PZC) of the $\mathrm{SiO}_{2}$ suspension.

Abundant evidence now supports the claim that at high $\mathrm{pH}$ charge reversal, CR3 reflects the metal hydroxide coating on the colloid substrate [20]. If sufficient metal ions are adsorbed at a $\mathrm{pH}$ suitable to form a complete coating of adsorbed metal hydroxide, then CR3 is the PZC of the metal hydroxide. Incomplete coating, due to a low concentration of metal or to a high concentration of colloidal substrate particles, reflects both coated and uncoated surfaces being mixed together. Thus, $\mathrm{CR} 3$ will occur at $\mathrm{pH}$ values at or below the $\mathrm{pH}_{\mathrm{pzc}}$ of the $\mathrm{Al}(\mathrm{OH})_{3}$, depending on the coverage achieved. According to Fig. 4, CR3 is made to approach the $\mathrm{pH}_{\mathrm{pzc}}$ of amorphous $\mathrm{Al}(\mathrm{OH})_{3}(9.0)$ [48] by increasing the $\mathrm{Al}(\mathrm{III})$ concentration. The CR3 of the colloid in the $1 \times 10^{-2} \mathrm{M}$ of $\mathrm{Al}(\mathrm{III}) / \mathrm{SiO}_{2}$ suspension is the same as the $\mathrm{pH}_{\mathrm{pzc}}$ of pure $\mathrm{Al}(\mathrm{OH})_{3}$, suggesting that $\mathrm{Al}(\mathrm{OH})_{3}$ completely covered the $\mathrm{SiO}_{2}$ particles.

In Fig. 4, the CR2 of the curves for $\mathrm{SiO}_{2}$ with $1 \times 10^{-3}$, $5 \times 10^{-3}$, and $1 \times 10^{-2} \mathrm{M}$ of $\mathrm{Al}(\mathrm{III})$ ranges from $\mathrm{pH} 2$ to 4 and increases as the concentration of $\mathrm{Al}(\mathrm{III})$ decreases. James and Healy [20] suggested that CR2 might indicate surface precipitation induced at a $\mathrm{pH}$ below that of bulk precipitation. They also used the relationship between standard free energy and the dielectric constants of the interfacial medium to derive the conclusion that the electric field of the surface-induced precipitation at the interface is established before bulk precipitation occurs, even though the solution is unsaturated with respect to this precipitated solid. Additionally, CR2 shifts to a lower $\mathrm{pH}$ as $\mathrm{Al}(\mathrm{III})$ concentration increases. Pugh and Bergström [49] also successfully interpreted the uptake of $\mathrm{Mg}(\mathrm{II})$ on $\alpha$-ultrafine silicon carbide and $\alpha$-alumina by applying James and Healy's model [20], and found that strong adsorption of $\mathrm{Mg}$ (II) occurred well below the bulk precipitation threshold. With respect to the $1 \times 10^{-3} \mathrm{M} \mathrm{Al}(\mathrm{III}) / \mathrm{SiO}_{2(s)}$ system, the CR2 in Fig. 4 is coincident with the point of the onset of surface precip-

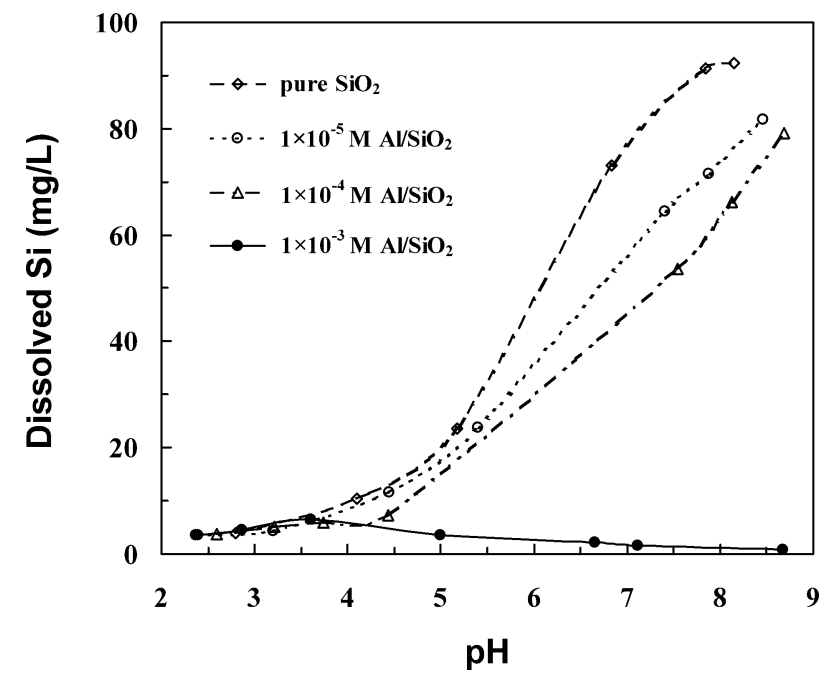

Fig. 5. Si dissolution of $\mathrm{SiO}_{2(s)}$ suspension with or without $\mathrm{Al}(\mathrm{III})$ over a pH range 2-9.

itation $(\sim \mathrm{pH} 4)$ in Fig. 2, which was determined by the divergence between the SCM/SPM predictions and the experimental data. Accordingly, these electrokinetic findings confirm that the SPM, based on the solid solution assumption, can successfully describe the transition from adsorption to bulk precipitation and indicate the onset of surface precipitation. Furthermore, the occurrence of CR2 near the IEP of $\mathrm{SiO}_{2(s)}$, almost obscuring it, could be regarded as representing the strong hydrolysis of $\mathrm{Al}(\mathrm{III})$ [20]. CR2 approaches CR1 in a strongly hydrolytic cation system but approaches CR3 in a weakly hydrolytic cation system.

\subsection{Effect of $\mathrm{Al}(\mathrm{III})$ on $\mathrm{SiO}_{2(s)}$ dissolution}

Fig. 5 shows the solubility characteristics of $1 \mathrm{~g} \mathrm{SiO}_{2(s)} / 1$ suspension with or without $\mathrm{Al}(\mathrm{III})$ over the $\mathrm{pH}$ range from 2 to 9 . The results imply that the release of silicate (represented as $\mathrm{Si} \mathrm{mg/l)} \mathrm{from} \mathrm{SiO}_{2(s)}$ solid increases with $\mathrm{pH}$, perhaps because the ionization of monosilicic acid enhances the dissolution of $\mathrm{H}_{4} \mathrm{SiO}_{4}$ from $\mathrm{SiO}_{2(s)}$, as illustrated below:

$$
\begin{aligned}
& \mathrm{SiO}_{2(s)}+2 \mathrm{H}_{2} \mathrm{O} \leftrightarrow \mathrm{Si}(\mathrm{OH})_{4(\text { aq })}, \\
& \mathrm{Si}(\mathrm{OH})_{4(\mathrm{aq})}+\mathrm{OH}^{-} \leftrightarrow \mathrm{Si}(\mathrm{OH})_{3} \mathrm{O}_{(\mathrm{aq})}^{-}+\mathrm{H}_{2} \mathrm{O} .
\end{aligned}
$$

Fig. 5 also indicates that the solubility of $\mathrm{SiO}_{2(s)}$ decreases as the $\mathrm{Al}$ concentration increases. In a system with low $\mathrm{Al}(\mathrm{III})$ concentration, such as $1 \times 10^{-4}$ and $1 \times 10^{-5} \mathrm{M}$, 
the concentration of the dissolved $\mathrm{Si}$ is slightly lower than that in a pure $\mathrm{SiO}_{2(s)}$ system. Stumm and Wollast [50] reported that a surface-coordinated metal ion, such as $\mathrm{Cu}$ (II) or $\mathrm{Al}(\mathrm{III})$, can block an oxide surface group, thus suppressing dissolution. Aqueous $\mathrm{Al}(\mathrm{III})$ forms an aluminosilicate complex on the reactive silica surface site [1, Eq. (16)]; and this complex more strongly suppresses dissolution of the reactive silica surface in an alkaline medium than that in an acidic medium, as compared the dissolution in pure $\mathrm{SiO}_{2}$ system.

$$
\underset{\substack{\text { reactive silica } \\ \text { surface site }}}{\operatorname{Si}(\mathrm{OH})}+\mathrm{Al}(\mathrm{OH})_{2}^{+} \leftrightarrow-\underset{\substack{\mid \\ \text { aluminosilicate } \\ \text { complex }}}{\operatorname{Si}} \operatorname{OAl}(\mathrm{OH})+\mathrm{H}^{+} .
$$

In the system with a high $\mathrm{Al}$ concentration of $1 \times 10^{-3} \mathrm{M}$, the concentration of dissolved $\mathrm{Si}$ is similar to that in the other systems below $\mathrm{pH} 4$, but much lower than that in the pure $\mathrm{SiO}_{2(s)}$ system above $\mathrm{pH} 4$. The concentration of the $\mathrm{Si}$ in this system at $\mathrm{pH} 8.6$ approaches $0.83 \mathrm{mg} / 1$, which is two orders of magnitude less than that of the pure $\mathrm{SiO}_{2(s)}$ system. Furthermore, the trend of the concentration of $\mathrm{Si}$ is quite different from that in other systems; the concentration increases with $\mathrm{pH}$ for $\mathrm{pH}<4$ but slightly drops as $\mathrm{pH}$ increases for $\mathrm{pH}>4$. These results imply that, while the surface aluminosilicate complex inhibits the dissolution of $\mathrm{SiO}_{2(s)}$, other mechanisms may be responsible for the dramatic restraint of the dissolution. Stein [51] also observed the dissolution reduction of $3 \mathrm{CaO} \cdot \mathrm{Al}_{2} \mathrm{O}_{3}$ solid by surface precipitation of $\mathrm{Al}(\mathrm{OH})_{3}$, but this reactivity reduction had been prevented by the presence of $\mathrm{SiO}_{2}$. This different trend of dissolution in $1 \times 10^{-3} \mathrm{M} \mathrm{Al}(\mathrm{III}) / \mathrm{SiO}_{2(s)}$, can be explained by the formation of an $\mathrm{Al}$ hydroxide surface precipitate, which leads to a passive film on the surface of $\mathrm{SiO}_{2(s)}$ and inhibits the corrosion of the $\mathrm{SiO}_{2(s)}$ surface by $\mathrm{OH}^{-}$ions.

\section{Conclusions}

$\mathrm{Al}(\mathrm{III})$ sorbs onto $\mathrm{SiO}_{2(s)}$ in different modes at various $\mathrm{pH}$ and $\mathrm{Al}(\mathrm{III})$ concentrations, as an $\mathrm{Al}\left(\mathrm{H}_{2} \mathrm{O}\right)_{6}^{3+}$ complex at low $\mathrm{pH}$ and $\mathrm{Al}(\mathrm{III})$ concentrations, hydrolyzed $\mathrm{Al}(\mathrm{OH})\left(\mathrm{H}_{2} \mathrm{O}\right)_{6}^{2+}$ complex at medium surface loading, and surface-induced precipitate at high sorption densities, confirming earlier suggestions that sorption mode changes with surface loading [17-19,27]. The modeling results of the SCM/SPM prediction showed that the solution from which the surface precipitate formed was not saturated with respect to $\mathrm{Al}(\mathrm{OH})_{3(s)}$. The SCM is an adequate model only when $\mathrm{Al}(\mathrm{III})$ sorption occurs as complexes binding at surface coordination sites of $\mathrm{SiO}_{2(s)}$, while inconsistency between predicted behavior and data exists when solution conditions (alkaline $\mathrm{pH}$, high sorbate/sorbent ratio) lead to the formation of surface precipitate. The SPM is capable of describing sorption over a wide range of $\mathrm{pH}$ and sorbate/sorbent ratios because this model allows species not only to sorb at the surface sites but also to form solid solutions on the
$\mathrm{SiO}_{2(s)}$ surface. Electrokinetic measurements suggest that no significant shift in electrophoretic mobility occurs during the specific adsorption of $\mathrm{Al}(\mathrm{III})$ onto $\mathrm{SiO}_{2(s)}$. However, under these solution conditions $\left(1 \times 10^{-3}, 5 \times 10^{-3}\right.$, and $1 \times 10^{-2} \mathrm{M} \mathrm{Al}(\mathrm{III})$ ), which lead to surface precipitation, three charge-reversal points exist and separately represent the IEP of $\mathrm{SiO}_{2}$, surface precipitation, and the $\mathrm{Al}$ hydroxide coating onto the $\mathrm{SiO}_{2}$ surface. In the $1 \times 10^{-3} \mathrm{M}$ $\mathrm{Al}(\mathrm{III}) / \mathrm{SiO}_{2(s)}$ system, CR2 (near $\mathrm{pH} 4$ ) is coincident with the onset $\mathrm{pH}$ of surface precipitation, as determined by the SPM. The dramatically low concentration of dissolved $\mathrm{Si}$ above $\mathrm{pH} 4$ in the $1 \times 10^{-3} \mathrm{M} \mathrm{Al}(\mathrm{III}) / \mathrm{SiO}_{2(s)}$ system is evidence of the formation of an Al hydroxide surface precipitate, which leads to the formation of a passive film on the surface of $\mathrm{SiO}_{2(s)}$, inhibiting the corrosion of the $\mathrm{SiO}_{2(s)}$ surface by $\mathrm{OH}^{-}$ions.

\section{Acknowledgments}

We thank the National Science Council of Taiwan, Republic of China, NSC 90-2218-E-131-013 and 91-2211-E131-002 for financial support.

\section{References}

[1] R.K. Iler, The Chemistry of Silica, Wiley, New York, 1979.

[2] C.T. Driscoll, K.M. Postek, in: G. Sposito (Ed.), The Environmental Chemistry of Aluminum, CRC Press, Boca Raton, FL, 1996, p. 363.

[3] D.W. Sparling, T.P. Lowe, P.G.C. Campbell, in: R.A. Yokel, M.S. Golub (Eds.), Research Issues in Aluminum Toxicity, Taylor \& Francis, Washington, DC, 1997, p. 47.

[4] G.F.V. Landeghem, M.E.D. Broe, P.C. D’hases, Clin. Biochem. 31 (1998) 385.

[5] P. Nayak, Environ. Res. Sect. A 89 (2002) 101.

[6] S. Bi, S. An, W. Tang, R. Xue, L. Wen, F. Liu, J. Inorg. Biochem. 87 (2001) 97.

[7] T.W. Swaddle, Coord. Chem. Rev. 219-221 (2001) 665.

[8] B.A. Dempsey, H. Sheu, T.M.T. Ahmed, J. Mentik, J. Am. Water Works Assoc. 77 (1985) 74.

[9] R.D. Letterman, S.R. Asolekar, Water Res. 24 (1990) 931.

[10] G. Sposito, The Environmental Chemistry of Aluminum, second ed., Lewis Publishers, Boca Raton, FL, 1996.

[11] P.R. Anderson, M.M. Benjamin, Environ. Sci. Technol. 24 (1990) 692.

[12] P.R. Anderson, M.M. Benjamin, Environ. Sci. Technol. 24 (1990) 1586.

[13] X. Meng, R.D. Letterman, Environ. Sci. Technol. 27 (1993) 970.

[14] X. Meng, R.D. Letterman, Environ. Sci. Technol. 27 (1993) 1924.

[15] D.A. Kulik, Geochim. Cosmochim. Acta 64 (2000) 3161.

[16] J.D. Reid, B. NcDuffie, Water Air Soil Pollut. 15 (1981) 375.

[17] C.J. Chisholm-Brause, P.A. O’Day, G.E. Brown Jr., G.A. Parks, Nature 348 (1990) 528.

[18] L.E. Katz, K.F. Hayes, J. Colloid Interface Sci. 170 (1995) 477.

[19] L.E. Katz, K.F. Hayes, J. Colloid Interface Sci. 170 (1995) 491.

[20] R.O. James, T.W. Healy, J. Colloid Interface Sci. 40 (1972) 42.

[21] M. Rasmusson, S. Wall, Colloids Surf. A Physicochem. Eng. Aspects 122 (1997) 169.

[22] Y. Xu, F.W. Schwartz, S.J. Traina, Environ. Sci. Technol. 28 (1994) 1472.

[23] G.E. Millward, R.M. Moore, Water Res. 16 (1982) 981. 
[24] W. Stumm, Chemistry of the Solid-Water Interface Processes at Mineral-Water and Particle-Water Interfaces in Natural Systems, Wiley-Interscience, New York, 1992.

[25] J.A. Davis, J.O. Leckie, J. Colloid Interface Sci. 67 (1978) 90.

[26] W. Stumm, E. Wieland, in: W. Stumm (Ed.), Aquatic Chemical Kinetics, Wiley-Interscience, New York, 1990, p. 367.

[27] N.T. Towle, J.R. Bargar, G.E. Brown Jr., G.A. Parks, J. Colloid Interface Sci. 187 (1997) 62.

[28] J. Laven, H.N. Stein, J. Colloid Interface Sci. 238 (2001) 8.

[29] K.G. Karthikeyan, H.A. Elliott, F.S. Cannon, Environ. Sci. Technol. 31 (1997) 2721.

[30] K.G. Karthikeyan, H.A. Elliott, J. Chorover, J. Colloid Interface Sci. 209 (1999) 72

[31] K.G. Karthikeyan, H.A. Elliott, J. Chorover, J. Colloid Interface Sci. 220 (1999) 88

[32] D.E. Yates, S. Levine, T.W. Healy, J. Chem. Soc. Faraday Trans. 70 (1974) 1807.

[33] L.S. Clesceri, A.E. Greenberg, A.D. Eaton, Standard Methods for the Examination of Water and Wastewater, APHA, AWWA, WEF, Washington, DC, 1998.

[34] W.H. Kuan, S.L. Lo, M.K. Wang, Water Sci. Technol. 42 (2000) 441.

[35] J.D. Allison, D.S. Brown, K.J. Novo-Gradac, MINTEQA2/ PRODEFA2, A Geochemical Assessment Model for Environmental Systems: Version 3.11 Database and Version 3.0 User's Manual, Environmental Research Laboratory, U.S. EPA, Athens, GA, 1991.
[36] D.A. Dzombak, F.M.M. Morel, Surface Complexation Modeling: Hydrous Ferric Oxide, Wiley, New York, 1990.

[37] K.J. Farley, D.A. Dzombak, F.M.M. Morel, J. Colloid Interface Sci. 106 (1985) 226

[38] D.C. Thorstenson, L.N. Plummer, Am. J. Sci. 277 (1977) 1203.

[39] P.D. Glynn, E.J. Reardon, Am. J. Sci. 290 (1990) 164.

[40] J.A. Meima, R.N.J. Comans, Environ. Sci. Technol. 32 (1998) 688.

[41] K.F. Hayes, C. Papelis, J.O. Leckie, J. Colloid Interface Sci. 125 (1988) 717.

[42] M. Berka, I. Bányai, J. Colloid Interface Sci. 233 (2001) 131.

[43] R.J. Crawford, I.H. Harding, D.E. Mainwaring, Langmuir 9 (1993) 3057.

[44] C.F. Baes, R.E. Mesmer, The Hydrolysis of Cations, Wiley, New York, 1976.

[45] D.A. Dzombak, F.M.M. Morel, J. Colloid Interface Sci. 112 (1986) 588.

[46] C.J. Chisholm-Brause, K.F. Hayes, A.L. Roe, G.E. Brown Jr., G.A. Parks, J.O. Leckie, Geochim. Cosmochim. Acta 54 (1990) 1987.

[47] A.L. Roe, K.F. Hayes, C.J. Chisholm-Brause, G.E. Brown, G.A. Parks, J.O. Leckie, Langmuir 7 (1991) 367.

[48] G.A. Parks, Chem. Rev. 65 (1965) 177.

[49] R.J. Pugh, L. Bergström, J. Colloid Interface Sci. 124 (1988) 570.

[50] W. Stumm, R. Wollast, Rev. Geophys. 28 (1990) 53.

[51] H.N. Stein, in: G.H. Stewart (Ed.), Science of Ceramics, Academic Press, London, 1967, p. 109. 